
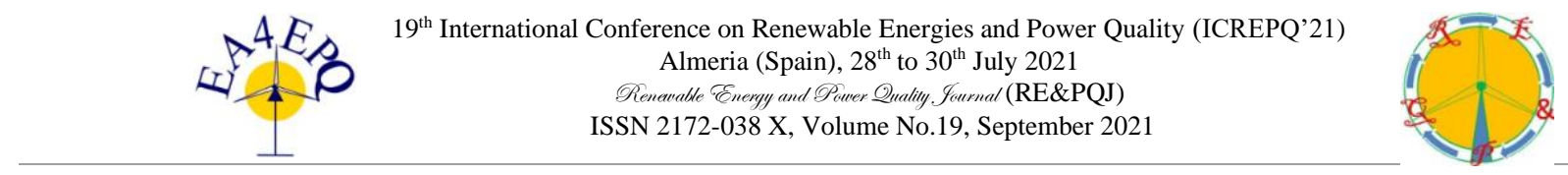

\title{
Survey on the Advancements of Dielectric Fluids and Experiment Studies for Distribution Power Transformers
}

\author{
S. Carvalhosa ${ }^{1}$, H. Leite ${ }^{1}$, F. Branco, Carlos A. Sá ${ }^{1}$, António M. Moura ${ }^{1}$, Ricardo C. Lopes ${ }^{2}$, Mário \\ Soares $^{3}$ \\ ${ }^{1}$ High Voltage Laboratory, Department of Electrical Engineering - Faculdade de Engenharia da Universidade do Porto \\ Campus of Asprela - 4200-465 Porto (Portugal) \\ e-mail: sacar@fe.up.pt, hleite@fe.up.pt, fabiobranco@fe.up.pt, cas@fe.up.pt, mmoura@fe.up.pt
}

${ }^{2}$ Efacec, Transformers R\&D

Apartado 1018 - 4466-952, São Mamede de Infesta, Portugal

e-mail: ricardol@efacec.com

${ }^{3}$ Redes Energéticas Nacionais, Asset Managment Department, Maia, 4470-259, Portugal

e-mail: mario.soares@ren.pt

\begin{abstract}
The main objective of this work is to summarize the most commonly used dielectric fluids in the power distribution transformers, as well as to discuss what are the latest and the rationale behind those trends. The favorable and unfavorable reasons for any choice behind each of those dielectric fluids will be discussed. Additionally, this work also advances the power distribution transformers health index most commonly used to assess the condition of the transformer.
\end{abstract}

Keywords - Dielectrics, Distribution Transformers, Mineral Oils, Ester Fluids, Dielectric Ageing Process, Health Indexes.

\section{Introduction}

Distribution Power Transformers - DPTs - dielectric fluids are one of the key elements to isolate the conductors from each other and the exterior tank. Insulation fluids act as a coolant as well, by absorbing the heat generated by the electric currents and releasing it via radiators and heat dissipaters placed in the exterior housing of the DPT. Insulation fluids must couple high dielectric strength with high thermal conductivity and be chemically stable under high temperatures.

Firstly, this work summarises the most used dielectric fluids used in DPTs and secondly, it surveys new novel solutions available in the market to act as the dielectric fluid of the DPT. Lastly, this paper presents the most common and used available laboratory tests, to compare the performance of new dielectric Natural Ester Fluids against Mineral Oils, assessing the ageing of Ester fluids and to calculate their health indexes throughout their expected life span.

\section{Brief History of Dielectric Fluids}

Mineral oil is the predominant category of dielectric fluids for the past 100 years [1], several variants exist within this group of dielectric and many other outside the category of mineral oils. The use of mineral oil became widespread because of its characteristics, appropriate insulating properties and compatibility with cellulose paper but also due to its relatively low cost [2]. The authors in [3] presents a timeline of the evolution of dielectric fluids that were used in DPTs:

- From 1890 to 1925 Paraffin-mineral oils were the most common;

- Between 1925 and 1930 Paraffin-mineral oils were replaced with Naphthenic-mineral oils;

- From the 30s to the 70s PCB based oils where the prevailing dielectric in use but in the 60s they started being heavily criticized and banned in 1978;

- In the 70s silicone oils and HTHs were introduced, and PCB oils were found to be toxic;

- In the late 80s esters were introduced an in the 90s research started on vegetable oils and natural esters;

- Between 1999 and 2001, 3 natural ester-based commercial products were patented;

- Mixture oil was introduced in the early 2000s and in 2006 the optimal mixture ratio was established;

- 2008 saw the introduction of Palm Fatty Acid Ester and the research on nanofluids began;

- In recent years, studies were conducted on the ageing of mixed oils and utility test setups were made with ester oils.

\section{Power transformer Dielectric fluid: Advantages and Disadvantages}

The main characteristics of the DPT insulation fluids or dielectric fluids are as follows [3-4]:

Paraffin-mineral oil:

- Advantages: Readily available; cheap;

- Disadvantages: High Pour point temperature; Low flash/fire point temperature; distilled from crude/petroleum oil.

Naphthenic-mineral oils:

- Adv: Lower pour point temperature when compared with Paraffin-mineral oil; readily available; cheap;

- Disadv: Low flash/fire point temperature, distilled from crude/petroleum oil.

Polychlorinated Biphenyl (PCBs): 
- Adv: Higher fire resistance than both predecessors; higher overall performance;

- Disadv: Highly toxic;

High-Temperature Hydrocarbons - HTH:

- Adv: Good performances under high temperatures, fire point above $300^{\circ} \mathrm{C}$;

- Disadv: Very low viscosity, this meant cooling systems needed to be redesign;

Silicone Oils (PCB replacement):

- Adv: Inert; thermally stable; electric properties similar do mineral oils, nontoxicity;

- Disadv: High cost;

Synthetic Esters:

- Adv: biodegradability; excellent thermal stability; low-temperature properties (e.g., pour point);

- Disadv: Novelty means they need more testing;

Natural Esters:

- Adv: Chemically stable; low viscosity (unsaturated types); biodegradable;

- Disadv: High viscosity (saturated types); very unstable in oxidation; like the synthetic version further testing is required but promising results have been obtained.

\section{Distribution Power Transformer Tests and Health Index Assessing Methodologies}

\section{A. Tests and Assessments for the Power Distribution Transformer dielectric fluid}

\section{a. Industrial Frequency Tests}

\section{Breakdown Voltage Test}

Breakdown voltage test is an AC overvoltage test that is applied to the dielectric fluid to assess their breakdown strength [4] and according to the American Society for Testing and Materials International - ASTM International "the dielectric breakdown voltage is a measure of the ability of an insulating liquid to withstand electrical stress. The power-frequency breakdown voltage of a liquid is reduced by the presence of contaminants such as cellulosic fibres, conducting particles, dirt, and water. A low result in this test method indicates the presence of significant concentrations of one or more of these contaminants in the liquid tested.".

\section{Partial Discharge Test}

Unlike in the breakdown voltage test in the Partial Discharge (PD) - Test the electrical discharge does not fully bridge the space between both electrodes or conductive surfaces. According to [5], PDs can lead to serious damage in the dielectric fluid and considerably reduce the lifespan of High Voltage equipment such as DPTs and can be caused by poor system design, manufacturing defects or contamination of the dielectric fluid [4]. The International Electrotechnical Commission - IEC - has a pre-established limit of PDs for all power equipment, this can be consulted in the IEC 60270 . The authors of [6] state that patterns within PDs can be useful criteria to assess the insulation system condition when using the specified index of the PD gravity.

\section{b. Lightning Impulse Test}

Lightning Impulse (LI) - test is one of the most important tests that are carried out on newly produce High-Voltage Power Transformers [12]. The LI Test can simulate how the dielectric fluid within the DPT will endure situations of overvoltage caused by natural phenomena like lightning strokes. Typically carried out using a multi-stage Marx Generator [7] or an Aperiodic Impulse Voltage Generator [8] https://doi.org/10.24084/repqj19.225 it is a difficult test to conduct in the field due to the size of the equipment required [9] but it's a necessary test to ensure the safe operation of the DPT to be tested. In [10] the author proposes a new method that does not require bulky equipment and relies instead on computer-based simulations.

\section{c. Dielectric Losses Factor Measurements}

According to [4] "Dielectric loss is the time rate at which electric energy is transformed into heat in a dielectric when it is subjected to an electric field. Dielectric loss is associated with real component (watts) losses in a dielectric". This test is widely accepted as a preventive maintenance test for dielectric fluid because new, good quality dielectric fluid such as a mineral oil will have a power factor of $0,05 \%$ at $20^{\circ} \mathrm{C}$, higher values can be associated with the presence of contaminants such as moisture, carbon and other conductive matter.

\begin{tabular}{cc} 
Table $1-$ Oil Grade Guide for test $[4]$ & Condition \\
Power Factor at $\mathbf{2 0}^{\circ} \mathbf{C}$ & Satisfactory for Service \\
\hline$<0,5 \%$ & Doubtful Condition \\
\hline$[0,5 \%-2 \%]$ & Reconditioning/Replacement \\
\hline$>2 \%$ &
\end{tabular}

d. DC Test

DC Test involves assessment of the solid winding insulation - paper, varnish - and the dielectric fluids used in DPT, and it provides valuable information about the general winding condition, such as moisture content and carbonization. There are sub-types of the DC Test like the Dielectric Absorption Test, and the DC High-Potential Test.

The Dielectric Absorption Test consists of applying voltage for $10 \mathrm{~min}$ and taking readings of resistance measurements at one-minute intervals, according to [4] when plotting the respective values the slope of the curve for a good insulation system is a straight line increasing concerning time, whereas a poor insulation system will have a curve that flattens out concerning time.

Table 2 - Dielectric Test Values for Routine Maintenance of Liquid-filled Transformers [4]

\begin{tabular}{ccc}
$\begin{array}{c}\text { Transformer } \\
\text { Winding Rated } \\
\text { Voltage (kV) }\end{array}$ & $\begin{array}{c}\text { Factory Test AC } \\
\text { Voltage (kV) }\end{array}$ & $\begin{array}{c}\text { Routine } \\
\text { Maintenance DC } \\
\text { Voltage (kV) }\end{array}$ \\
\hline 1.2 & 10 & 10.40 \\
\hline 2.4 & 15 & 15.60 \\
\hline 4.8 & 19 & 19.76 \\
\hline 8.7 & 26 & 27.04 \\
\hline 15.0 & 34 & 35.36 \\
\hline 18.0 & 40 & 41.60 \\
\hline 25.0 & 50 & 52.00 \\
\hline 34.5 & 70 & 72.80 \\
\hline
\end{tabular}

The DC High-Potential - Hi-Pot - Test is performed has a mean to assess the state of the winding insulation. Reference [4] describes extensively how the Hi-Pot test is conducted and being a destructive test when performed the following considerations must be made:

Assume that the solid insulation breakdown will occur; Replacement parts must be available when performing the Hi-Pot test;

- Qualified personnel must be present when performing the Hi-Pot test;

Will the Hi-Pot test cause a longer outage than what was previously planned? RE\&PQJ, Volume No.19, September 2021 


\section{e. Temperature Assessments}

Temperature assessment should be carried out during and in between the tests mentioned in the previous sections and are carried out using thermocouples connected to the Power Transformer housing shown in Figure 1.

\section{f. Main Testing Standards and Norms}

All tests and assessments described in a to e must be performed in compliance with the following standards:

Table 3 - Norms and Standards according to each Agency [4] [11]

\begin{tabular}{ll} 
ASTM International & IEC \\
\hline D1816 & $60060-1 / 2010$ \\
\hline D877 / D877M & $60060-2 / 2010$ \\
\hline D3300-20 & $60060-3 / 2006$ \\
\hline & 60156 \\
\hline & 60247 \\
\hline & 60296 \\
\hline & $60076-3$ \\
\hline
\end{tabular}

\section{B. Health Assessment Methods \& Health Indexes}

It is advantageous to have updated information about the health status of every DPT because failures and outages can be very costly for the System Operators but so is maintenance so health indexes - HI - are a useful tool to determine maintenance schedules and units that need replacement, reducing instances of under or over investment, for that purpose Table 4 presents different HI methodologies proposed in [12]:

Table 4 - Input Data for Health Indexing Methodologies

\begin{tabular}{rccc} 
& A & B & C \\
\hline Dissolved Gas Analysis & $\mathrm{x}$ & $\mathrm{x}$ & $\mathrm{x}$ \\
\hline Oil Quality & $\mathrm{x}$ & $\mathrm{x}$ & $\mathrm{x}$ \\
\hline Furfural & $\mathrm{x}$ & $\mathrm{x}$ & $\mathrm{x}$ \\
\hline Load History & $\mathrm{x}$ & $\mathrm{x}$ & \\
\hline Power Factor & $\mathrm{x}$ & & \\
\hline Maintenance & $\mathrm{x}$ & \\
\hline General Condition & $\mathrm{x}$ & \\
\hline
\end{tabular}

Together with the tests, presented in chapter 0 , on insulation fluids, the best $\mathrm{HI}$ methodology will be used on the viability of replacing the current mineral oil for the ester fluids.

\section{a. Dissolved Gas Analysis}

Liquid Dielectrics, such as mineral oils, undergo decomposition as they age. Dissolved Gas Analysis - DGA measures the gas concentration in oil that are formed by those decomposition processes. Typically, the following gases are can be formed [13]:

$$
\begin{array}{ll}
\text { Hydrogen }-\mathrm{H}_{2} ; & \text {. Methane }-\mathrm{CH}_{4} ; \\
\text {. Ethylene }-\mathrm{C}_{2} \mathrm{H}_{4} ; & \text {. Ethane }-\mathrm{C}_{2} \mathrm{H}_{6} ; \\
\text {. Acetylene }-\mathrm{C}_{2} \mathrm{H}_{2} ; & \text {. Carbon Monoxide }-\mathrm{CO} ;
\end{array}
$$

Each gas, and its concentration, is associated with a different type of fault depending on the dielectric fluid, for most mineral oils, for example, we can expect the following concentrations:

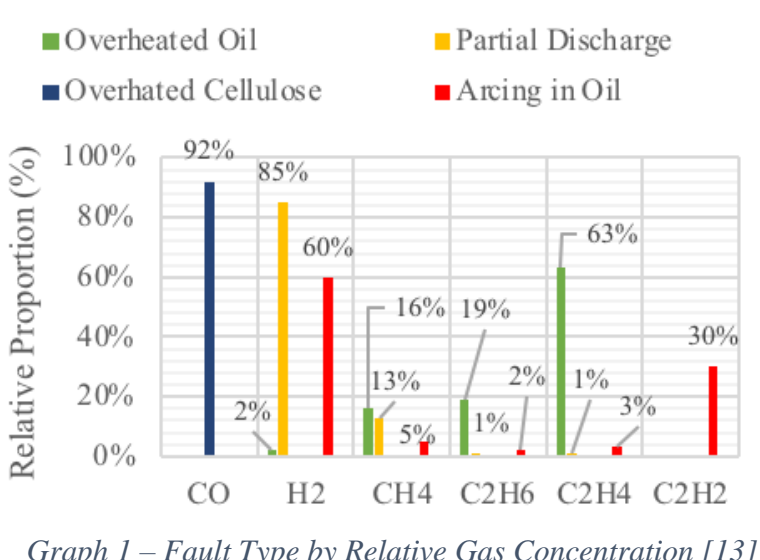

Graph 1 - Fault Type by Relative Gas Concentration [13]

Other studies such as [14], [15] and [16] provide further information on other Dielectric Fluids such as Natural Esters.

Table 5-Score $S_{i}$ for Gas Levels [ppm] [17] [18]

\begin{tabular}{rcccccc}
$\mathbf{S}_{\mathbf{i}}=>$ & $\mathbf{1}$ & $\mathbf{2}$ & $\mathbf{3}$ & $\mathbf{4}$ & $\mathbf{5}$ & $\mathbf{6}$ \\
\hline \multirow{2}{*}{$\mathbf{H}_{2}$} & $<$ & $100-$ & $200-$ & $300-$ & $500-$ & $>700$ \\
& 100 & 200 & 300 & 500 & 700 & \\
\hline \multirow{2}{*}{$\mathbf{C H}_{\mathbf{4}}$} & $<75$ & $\begin{array}{c}75- \\
125\end{array}$ & $\begin{array}{c}125- \\
200\end{array}$ & $\begin{array}{c}200- \\
400\end{array}$ & $\begin{array}{c}400- \\
600\end{array}$ & $>600$ \\
\hline \multirow{2}{*}{$\mathbf{C}_{2} \mathbf{H}_{\mathbf{6}}$} & $<65$ & $65-80$ & $\begin{array}{c}80- \\
100\end{array}$ & $\begin{array}{c}100- \\
120\end{array}$ & $\begin{array}{c}120- \\
150\end{array}$ & $>150$ \\
\hline \multirow{2}{*}{$\mathbf{C}_{2} \mathbf{H}_{\mathbf{4}}$} & $<50$ & $50-80$ & $80-$ & $100-$ & $150-$ & $>200$ \\
\hline $\mathbf{C}_{2} \mathbf{H}_{2}$ & $<3$ & $3-7$ & $7-35$ & $35-50$ & $50-80$ & $>80$ \\
\hline \multirow{2}{*}{$\mathbf{C O}$} & $<$ & $350-$ & $700-$ & $900-$ & $1100-$ & $>$ \\
& 350 & 700 & 900 & 1100 & 1400 & 1400 \\
\hline
\end{tabular}

Based on Table 5 it is possible to score the dielectric fluid based on the amount of Dissolved Gas and then using Eq. 1 it is possible to associate de overall scoring with a Rating using Table 6:

Table 6 - Power Distribution Transformer based on DGA [17] [18]

\begin{tabular}{cll} 
Rating & Condition & DGA Scoring \\
\hline A & Good & $<1.2$ \\
\hline B & Acceptable & $1.2-1.5$ \\
\hline C & Need Caution & $1.5-2$ \\
\hline D & Poor & $2-3$ \\
\hline E & Very Poor & $>3$ \\
\hline
\end{tabular}

The final rating in Table 5 is a weighted average of the scoring obtained for each one of the gases:

$$
\text { Scoring }=\frac{\sum_{i=1}^{6}\left(S_{i} \times W_{i}\right)}{\sum_{i=1}^{6} W_{i}} \quad[18] \quad \text { Eq. } 1
$$

Some authors also consider the presence of $\mathrm{CO}_{2}$, in that case the sum would have to accommodate the addition and $\mathrm{W}_{\mathrm{i}}$ is the weight attributed to each gas accordingly to the importance of their presence, because the reason for the presence of each gas varies as previously mentioned.

\section{b. Oil Quality}

This assessment is composed by 6 parameters:

Table 7 - Assess Parameters for Oil Quality [18]

\begin{tabular}{rll}
\multicolumn{1}{c}{ Parameter } & ASTM Norm & IEC Norm \\
\hline DBV (1) & D877 \& D1816 & 60156 \\
\hline Water Content & D1533 & 60814 \\
\hline Dissipation Factor & D924 & 60247 \\
\hline Interfacial Tension & D971 & ISO 6295 \\
\hline Acidity Test & D644 \& D974 & 62021 \\
\hline Color & D1500 & ISO 2049
\end{tabular}

(1) DBV: Dielectric Breakdown Voltage; 
The ASTM International norms are recommended by the Institute of Electrical and Electronics Engineers - IEEE and the IEC norms are recommended by the Conseil International des Grands Réseaux Électriques - CIGRE and they can be consulted in Table 7. Typical values and respective grading for each of the parameters can be consulted in the following papers - [18], [17] and [4].

\section{c. Furfural Concentration in Dielectric Fluid Anaysis}

Evaluating the state of the insulating paper is a proven way to assess the operation reliability and residual life expectancy of a DPT, however, testing the insulating paper directly is, in almost every case, unfeasible.

Along the decades several testing methods have been suggested and since the $1980 \mathrm{~s}$, Furfural $-\mathrm{C}_{5} \mathrm{H}_{4} \mathrm{O}_{2}-$ has been proposed as clear marker of cellulose aging in power transformers [19], also known as 2-FAL, the concentration of this chemical is closely related with the degree of polymerization - DP - of insulation paper.

Furfural and related compounds concentration assessment should be performed according to either the IEC 61198 norm or the ASTM 5837 norm.

Rating codes have been proposed for furfural tests that can be correlated with aging when furfural tests are not available:

Table 8 - Furfural Test Rating or Age Rating when Test Results are not available [17] [18]

\begin{tabular}{ccc} 
Rating Code & Furaldehyde [ppm] & Age in years \\
\hline A & $0-0.1$ & $<20$ \\
\hline B & $0.1-0.25$ & $20-40$ \\
\hline C & $0.25-0.5$ & $40-60$ \\
\hline D & $0.5-1$ & $>60$ \\
\hline E & $>1$ & \\
\hline
\end{tabular}

\section{d. Distribution Power Transformer Load History}

In current literature Load History is represented by Load Factor - LF - that is calculated using the ratio of monthly peak load $-S_{\mathrm{i}}-$ and rated load $-S_{B}-$ for every month [20], where LF is calculated in the following manner:

$$
L F=\frac{\sum_{i=0}^{4}(1-i) \cdot N_{i}}{N_{i}} \quad \text { Eq. } 2
$$

The value of $\mathrm{Ni}$ can be consulted in the IEC 354, IEEE C57.91-1995 standard which has the following distribution:

$$
\begin{aligned}
& \mathrm{N}_{0}: \mathrm{S}_{\mathrm{i}} / \mathrm{S}_{\mathrm{B}}<0.6 ; \\
& \mathrm{N}_{1}: 0.6<\mathrm{S}_{\mathrm{i}} / \mathrm{S}_{\mathrm{B}}<1 ; \\
& \mathrm{N}_{2}: 1<\mathrm{S}_{\mathrm{i}} / \mathrm{S}_{\mathrm{B}}<1.3 ; \\
& \mathrm{N}_{3}: 1.3<\mathrm{S}_{\mathrm{i}} / \mathrm{S}_{\mathrm{B}}<1.5 ; \\
& \mathrm{N}_{4}: 1.5<\mathrm{S}_{\mathrm{i}} / \mathrm{S}_{\mathrm{B}} .
\end{aligned}
$$

After calculating LF it is possible to associated the respective rating code:

Table 9 - Load Factor Rating Code [18]

\begin{tabular}{cc} 
Rating Code & Load Factor \\
\hline A & $>3.5$ \\
\hline B & $2.5-3.5$ \\
\hline C & $1.5-2.5$ \\
\hline D & $0.5-1.5$ \\
\hline E & $<0.5$ \\
\hline
\end{tabular}

\section{e. Power Factor}

The purpose of conducting Power Factor Tests (PF) Tests - is to ascertain if the equipment (DPT) was correctly installed, determine the need for pre-emptive maintenance or repairs as well as to track ongoing deterioration of the https://doi.org/10.24084/repqj19.225 equipment along its lifetime. These tests are conducted at the same frequency as the equipment operates, 50 or $60 \mathrm{~Hz}$, and for this reason, this test is categorized as an alternating current test - AC Test - and it's considered a non-destructive test - NDT - because the voltage used when performing these assessments do not exceed line-to-neutral voltages of the equipment.

The compliance norm for this test is the same as the Dissipation Factor in Table 7.

The PF value can be described as [21]:

$$
P F=\frac{\text { Watts Absorbed in Insulation }}{\text { Applied Voltage } \times \text { Charge Current }} \text { Eq. } 3
$$

The formula described in Eq. 2 can be rewritten in a more useful way:

$$
P F=\cos (\theta)=\frac{I_{\text {reactive }}}{I} \quad \text { Eq. } 4
$$

Power Factor Tests are often conducted together with Dissipation Factor Tests:

$$
D F=\tan (\delta)=\frac{I_{\text {reactive }}}{I_{\text {capacitive }}}
$$

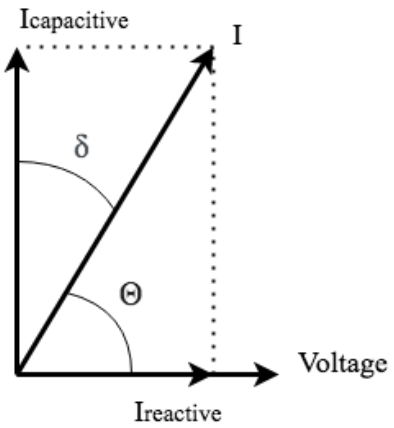

Graph 2 - Test Current Components

According to [21] for low power factor insulation, $\mathrm{I}_{\mathrm{c}}$ and I are approximately the same magnitudes because the loss component $I_{r}$ is very small, regarding $P F$ value when designing insulation systems, the target value is the closest possible to 0 and oil-paper insulation systems will exhibit flat capacitance and loss curve concerning the test voltage.

When testing the dielectric fluid inside a DPT these are the configurations for the test:

High-voltage winding to ground;

High-voltage to low-voltage winding;

High-voltage to tertiary-voltage winding;

Low-voltage winding to ground;

Low-voltage to tertiary-voltage winding;

Tertiary-voltage winding to ground insulation.

After conducting all the measurements, the highest value is considered $-\mathrm{PF}_{\max }$ - and the rating is giving accordingly:

Table 10 - Highest Power Factor measured Rating [18]

\begin{tabular}{cc}
$\begin{array}{c}\text { Rating } \\
\text { Code }\end{array}$ & $\begin{array}{c}\text { Maximum PF } \\
{[\%]}\end{array}$ \\
\hline $\mathrm{A}$ & $<0.5 \%$ \\
\hline $\mathrm{B}$ & $0.5-1 \%$ \\
\hline $\mathrm{C}$ & $1-1.5 \%$ \\
\hline $\mathrm{D}$ & $1.5-2 \%$ \\
\hline $\mathrm{E}$ & $>2 \%$ \\
\hline
\end{tabular}




\section{f. Maintenance - Previous Interventions}

Data reporting maintenance actions in previous years is valuable information that can be considered when computing a Health Index.

The authors in [18] proposed a ranking system where a DPT that had no maintenance needs in the 5 previous years will be attributed an A rank and a DPT that required more than 6 maintenance interventions will be attributed an $\mathrm{E}$ rank.

According to [22], failures that occur on a DPT are the following and can occur at the resulting rate:

$\square$ Insulation
$\square$ Winding
$\square$ Core
$\square$ Bushing
$\square$ Tap Changer
$\square$ Cool ing System
$\square$ Tank
$\square$ Others

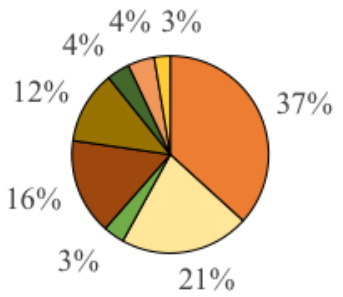

Graph 3 - Power transformer component failures in the period 2003-2013 [22].

The "Others" type of failure includes operational errors, lack of maintenance and Protection System failures.

It is important to emphasize that this data and rate of failures can vary if other countries and respective Distribution/Transport Grids are considered.

\section{g. Distribution Power Transformer Components General Condition}

This parameter is the most abstract of all the parameters considered because it depends, to some extent, on the visual inspection of the DPT by a capable technician therefore it depends on an opinion that can vary depending on the observer, to reduce this variability a checklist must be used that provides guidelines to what should be assessed [18] [22] and it comprises bbushings, gaskets and seals condition, main tank and oil tank corrosion cooling system, foundation, hrounding and connectors condition, presence of oil leaks, oil level and oil temperature, buchholz relays, displays alarm and trip signals indicators condition.

The previous sub-parameters should be assessed thoroughly and are rated similarly to the previous parameters where, if the subject is in good condition, it will be rated with an $\mathrm{A}$ and if the subject requires repair, it will be rated an E.

\section{Dielectric Fluid Testing Station}

Laboratory tests will be carried out on a DPT housing with three Rogoswki type electrodes pairs inside as shown in the following Figure 1.
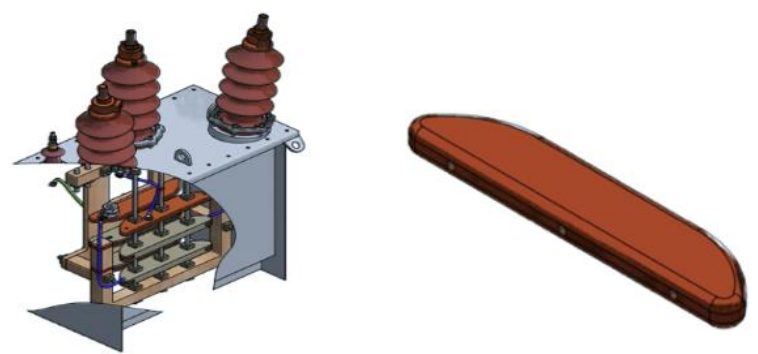

Figure 1 - Power Distribution transformer housing interior [left]; Rogoswki type electrode, bare copper [right]

The electrodes will have different finishes applied, one with $0,07 \mathrm{~mm}$ varnish coating, the other with 16 paper sheets with $0,01 \mathrm{~mm}$ thickness and lastly one bare copper electrode.
For each set of tests, the transformer housing is filled with 1 of 4 different kinds of dielectric fluid, and after each battery of test the housing must be emptied of all-dielectric fluid, thoroughly clean to remove any remnants of the dielectric fluid that was previously studied, all the electrodes must be checked due to the destructive nature of some of the tests that were carried out and if necessary repairs must be made, finally transformer housing is filled with the next dielectric fluid that will be analysed. The dielectric fluids that will be analysed in future work can be consulted in the following table:

Table 11 - Reference breakdown voltage values for the dielectric fluids under analysis [11]

\begin{tabular}{|c|c|c|c|c|c|}
\hline & & $\begin{array}{c}\text { Specific } \\
\text { Value }\end{array}$ & $\begin{array}{c}\text { Typical } \\
\text { Value }\end{array}$ & $\begin{array}{c}\text { Typical } \\
\text { Value }\end{array}$ & Norm \\
\hline \multirow{2}{*}{$\begin{array}{c}\text { Mineral } \\
\text { Oil }\end{array}$} & $\begin{array}{c}\text { Nynas Nitro } \\
\text { Taurus }\end{array}$ & $70 \mathrm{kV}$ & $>70 \mathrm{kV}$ & - & \multirow{4}{*}{ 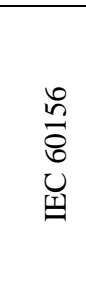 } \\
\hline & $\begin{array}{c}\text { Ergon } \\
\text { Hyvolt I }\end{array}$ & $70 \mathrm{kV}$ & $75 \mathrm{kV}$ & - & \\
\hline $\begin{array}{c}\text { Natural } \\
\text { Ester }\end{array}$ & $\begin{array}{c}\text { Envirotemp } \\
\text { FR3 }\end{array}$ & - & - & $73 \mathrm{kV}$ & \\
\hline $\begin{array}{l}\text { Synthetic } \\
\text { Ester }\end{array}$ & Midel 7131 & - & - & $>75 \mathrm{kV}$ & \\
\hline
\end{tabular}

\section{Final Remarks}

Literature review shows there is extensive information, norms and standards regarding testing and assessments of mineral oil used as a dielectric fluid in Distribution Power Transformers - DPT - and other electrical equipment. However, regarding the dielectric Ester Fluids (either natural or synthetic) there is lack of information regarding the use of norms and standards on Ester Fluid Testing.

In sum, future work will need to comprising the aforementioned tests, assessments and health indexing analysis is expected to obtain answers for the following questions:

Are the Ester Fluid options analysed a viable replacement for the mineral oils that are used today in DPTs?

Can the current Health Indexing methodologies be applied to Ester Fluids and help determine the optimal point in a DPTs life to replace the current mineral oils with Ester based oils?

Are the current norms and standards applicable when testing and assessing how Ester fluids perform?

Will the values observed when testing Ester Fluids be the same as when tests are carried out with Mineral Oils and will it be possible to draw the same conclusions as in the Partial Discharge Tests or the Furfural Tests?

\section{References}

[1] R. Liu, C. Törnkvist, V. Chandramouli, O. Girlanda and L. A. Petterson, "Ester Fluids as Alternative for Mineral Oil: The Difference in Streamer Velocity and LI Breakdown Voltage," in Annual Report Conference on Electrical Insulation and Dielectric Phenomena, Virginia Beach, 2009.

[2] A. Ciuriuc, M. S. Vihacencu, L. M. Dumitran and P. V. Notingher, "Comparative study on power transformers vegetable and mineral oil ageing," in International Conference on Applied and Theoretical Electricity (ICATE), Craiova, 2012. 
[3] U. M. Rao, I. Fofana, T. Jaya, E. M. Rodriguez-Celis, J. Jalbert and P. Picher, "Alternative Dielectric Fluids For Transformer Insulation System: Progress, Challenges and Future Prospects," IEEE Access, pp. 184552-18457, 1612 2019.

[4] P. Gill, Electrical Power Equipment Maintenance and Testing, 2nd Edition ed., Boca Raton, Florida: CRC Press, 2009.

[5] W. J. K. Raymond, H. A. Illias, H. A. Bakar and H. Mokhlis, "Partial discharge classifications: Review of recent progress," Measurment, vol. 68, pp. 164-181, 2015.

[6] M. Shafiq, G. A. Hussain, L. Kütt and M. Lehtonen, "Effect of geometrical parameters on high frequency performance of Rogowski coil for partial discharge measurements," Measurment, vol. 49, pp. 126-137, 2013.

[7] S. C. Glidden and H. D. Sanders, "Solid State Marx Generator," in Conference Record of the 2006 TwentySeventh International Power Modulator Symposium, Arlington, 2006.

[8] J. Li, L. Zhang, Y. Jin and X. Yao, "Breakdown characteristics of transformer oil in a uniform field under oscillating impulse voltage," Transactions on Dielectrics and Electrical Insulation, vol. 24, no. 2, pp. 984-990, April 2017.

[9] X. Zhang, M. Shi, C. He and J. Li, "On Site Oscillating Lightning Impulse Test and Insulation Diagnose for Power Transformers," Transactions on Power Delivery, vol. 35, no. 5, pp. 2548-2550, October 2020.

[10] H. R. Mirzaei, "A Simple Fast and Accurate Simulation Method for Power Transformer Lightning Impulse Test," TRANSACTIONS ON POWER DELIVERY, vol. 34, no. 3, pp. 1151-1160, June 2019.

[11] B. Canhoto, "Guia de Especificações Técnicas para os Ensaios Dielétricos em Espécimes e Subestruturas Isolantes," FEUP, Porto, 2020.

[12] H. M. R. Campelo, H. D. Leite and N. Silva, "Power Transformer Health Index Assessment - Transmission Case Studies," in EuroTechCon, Glasgow, 2017.

[13] S. Bustamante, M. Manana, A. Arroyo, P. Castro, A. Laso and R. Martinez, "Dissolved Gas Analysis Equipment for Online Monitoring of Transformer Oil: A Review," in Sensors, Switzerland, 2019.

[14] N. A. Gómez, H. M. Wilhelm, C. C. Santos and G. B. Stocco, "Dissolved Gas Analysis (DGA) of Natural Ester Insulating Fluids with Different Chemical Compositions," IEEE Transactions on Dielectrics and Electrical Insulation, vol. 21, no. 3, pp. 1071-1078, June 2014.

[15] I. Khan, Z. Wang, J. Dai, I. Cotton and S. Northcote, "Fault Gas Generation in Ester based Transformer Fluids and Dissolved Gas Analysis (DGA)," in International Conference on Condition Monitoring and Diagnosis, Beijing, 2008.

[16] L. Loiselle, U. M. Rao and I. Fofana, "Gassing Tendency of Fresh and Aged Mineral Oil and Ester Fluids under Electrical and Thermal Fault Conditions," Energies, vol. 13 , no. $13,2020$.
[17] I. S. Hernanda, A. Mulyana, D. A. Asfani, I. Negara and D. Fahmi, "Application of Health Index Method for Transformer Condition Assessment," in TENCON 2014 2014 IEEE Region 10 Conference, Bangkok, 2014.

[18] A. Naderian, S. Cress, R. Piercy, F. Wang and J. Service, "An Approach to Determine the Health Index of Power Transformers," in Conference Record of the 2008 IEEE International Symposium on Electrical Insulation, Vancouver, 2008.

[19] L. Yang, Y. Lin, R. Liao, X. Zhao, W. Sun and Y. Zhang, "Effects of Temperature and Aging on Furfural Partitioning in the Oil-paper System of Power Transformers," IEEE Transactions on Dielectrics and Electrical Insulation, vol. 23, no. 3, pp. 1393-1401, June 2016.

[20] K. Chitnavis and D. N. R. Bhasme, "Review of Critical Analysis for Life Estimation of Power Transformer," 2017 4th International Conference on Power, Control and Embedded Systems, pp. 1-6, 2017.

[21] A. Rojas, "Power Factor Testing in Transformer Condition Assessment -Is There a Better Way?," in 2006 IEEE/PES Transmission \& Distribution Conference and Exposition: Latin America, Caracas, 2006.

[22] R. Murugan and R. Ramasamy, "Understanding the power transformer component failures forhealth index-based maintenance planning in electric utilities," Engineering Failure Analysis, vol. 96, pp. 274-288, 2018.

[23] D. S. Roesser, "Natural Ester Fluids: Flowing into the Mainstream," Electric Energy T\&D Magazine, vol. 18, no. 4, pp. 32-35, 2014.

[24] N. Malik, A. Al-Arainy and M. Qureshi, Electrical Insulation in Power Systems, Riyadh, Saudi Arabia: Taylor and Francis, 1998.

[25] T. Rouse, "Mineral Insulating Oil in Trasnformers," IEEE Electric Insulation Magazine, vol. 14, no. 3, pp. 6-16, 1998.

[26] C. J.George, G. F.Bennett, D. Simoneaux and W. J.George, "Polychlorinated biphenyls a toxicological review," Journal of Hazardous Materials, vol. 18, no. 2, pp. 113-144, 1988.

[27] I. Fernández, A. Ortiz, AlfredoOrtiz, F. Delgado, C. Renedo and S. Pérez, "Comparative evaluation of alternative fluids for power transformers," Electric Power Systems Research, vol. 98, pp. 58-69, 2013.

[28] Y. Bertrand and L. Hoang, "Vegetal Oils as Substitute for Mineral Oils," in Proceedings of the 7th Internatinal Conference on Properties and Applications of Dielectric Materials, Nagoya, 2003. 